Nevşehir Bilim ve Teknoloji Dergisi Cilt 5(1) 10-15 2016

DOI: 10.17100/nevbiltek.52239

URL: http://dx.doi.org/10.17100/nevbiltek.52239

\title{
Scabiosa hispidula Boiss. (Caprifoliaceae) Türüne Ait Anatomik Bir Çalışma
}

\author{
Yurdanur AKYOL ${ }^{1, *}$, Okan KOCABAŞ ${ }^{2}$, Esra KAYACAN² ${ }^{2}$ Ersin MINARECİ ${ }^{2}$, Canan ÖZDEMIR ${ }^{2}$ \\ ${ }^{1}$ Milli Eğitim Bakanlığı, Manisa Hasan Türek Anadolu Lisesi, Yunusemre, Manisa, Türkiye \\ ${ }^{2}$ Celal Bayar Üniversitesi Fen Edebiyat Fakültesi Biyoloji Bölümü, 45030, Muradiye, Manisa, Türkiye
}

Öz

Taksonomik açıdan karışıklıklar içeren Scabiosa L. cinsi, Caprifoliaceae familyasının en önemli cinslerinden biridir ve ülkemizde yaklaşık 36 takson ile temsil edilmektedir. Bu çalışmanın amacı Mayıs-Eylül ayları arasında çiçeklenen ve tek yıllık bir bitki olan Scabiosa hispidula Boiss. türünün, anatomik özelliklerinin belirlenmesidir. Bu amaçla kök, gövde ve yapraklardan alınan enine kesitler incelenerek fotograflandırılmıştır. Gövde enine kesitinde gözlenen salgı tüyleri ve hidatotlar karakteristiktir.

Anahtar Kelimeler: Scabiosa hispidula, Caprifoliaceae, bitki anatomisi

\section{An Anatomical Study on Scabiosa hispidula Boiss. (Caprifoliaceae)}

\section{Abstract}

Scabiosa L. genus contains taxonomic confusions is one of the most important genus of the family Caprifoliaceae and is represented by 36 taxon in Turkey. The aim of this study was to determine the anatomical features of Scabiosa hispidula Boiss. with an annual and flowering between May and September. For this purpose, cross-sections of root, stem and leaf parts of the plant were examined and demonstrated by photographs. The glandular hairs and hydathode was observed in the cross-section of stem are characteristics for S. hispidula.

Keywords: Scabiosa hispidula, Caprifoliaceae, plant anatomy.

*e-mail: yurdanur45@gmail.com 


\section{Giriş}

Caprifoliaceae Juss. familyası 6 alt familya içermektedir. Bunlardan Dipsacoideae Eaton yaklaşık 9 cins ve 320 tür içeren; Avrupa, Afrika ve Asya'da yayılış gösteren bir alt familyadır [1, 2]. Bu alt familyaya dahil olan Scabiosa L. cinsi ise Türkiye’de yaklaşık 36 takson ile temsil edilmektedir [3]. Familyanın en önemli üyelerinden biri olan Scabiosa cinsinin taksonomik açıdan karışıklıklar içerdiği belirtilmektedir [4, 5]. Anatomik karaktelerin bitki taksonomisindeki önemi eskiden beri bilinmektedir [6, 7]. Bu karakterlerin belirlenmesi taksonomik çalışmalara katkı sağlayacaktır. Scabiosa cinsinin çeşitli taksonları, kanser tedavisinde ve böbrek taşlarının düşürülmesinde uzun yıllardır halk ilacı olarak kullanılmaktadır [5, 8]. Cinse ait taksonların etnobotanik açıdan kullanımı dışında süs bitkisi olarak ta kullanıldığı bilinmektedir [9, 10]. Çalışmanın konusunu oluşturan tek yıllık bir bitki olan S. hispidula türü, geniş parçalı yaprakları, kaliksin iç kısmının tüylü oluşu, involuselde yayılıcı tüylerin ve 1,5 mm uzunluğunda koronasının bulunuşu gibi özellikleri bakımından diğer türlerden morfolojik olarak ayırt edilmektedir.

Scabiosa hispidula Boiss. türü ile ilgili yapılan literatür taramasında, ayrıntılı bir anatomi çalışmasına rastlanmamıştır. Türün kök, gövde ve yaprak organları anatomik açıdan ayrıntılı bir şekilde ilk kez bu çalışmada incelenmiştir.

\section{Materyal ve Metot}

Bitki örnekleri İzmir İli’nin Urla İlçesi’nden 2014 yılında doğal populasyonundan toplandı (Şekil 1). Türün tayini "Flora of Turkey” adlı esere göre yapılmıştır [11]. Bitkinin taze örneklerinin bir kısmı anatomik çalışmalar için kullanılmış ve bir kısmı da kurutularak herbaryum örneği haline getirilmiştir. Anatomik çalışmalar için bitki materyalleri \%70’lik etanolde fikse edilmiştir. Mikroskobik gözlemler için parafin metodu ve el kesiti kullanılmıştır [12]. Parafin metodu kullanılarak hazırlanan kesitler, rotary mikrotom yardımı ile 10-15 $\mu \mathrm{m}$ kalınlığında alınmıştır. Tüm kesitler belirli oranlarda hazırlanan safranin/fast-green ikili boyama sistemine göre boyanarak Leica DM3000 marka kameralı mikroskop ile fotoğraflandırılmıştır [13]. Kök, gövde ve yaprak organlarına ait incelenen preparatlarda; çeşitli hücrelerin boyutları mikrometrik oküler yardımı ile ölçülerek minimum, maksimum, ortalama ve standart sapma değerleri hesaplanmıştır (Tablo 1).

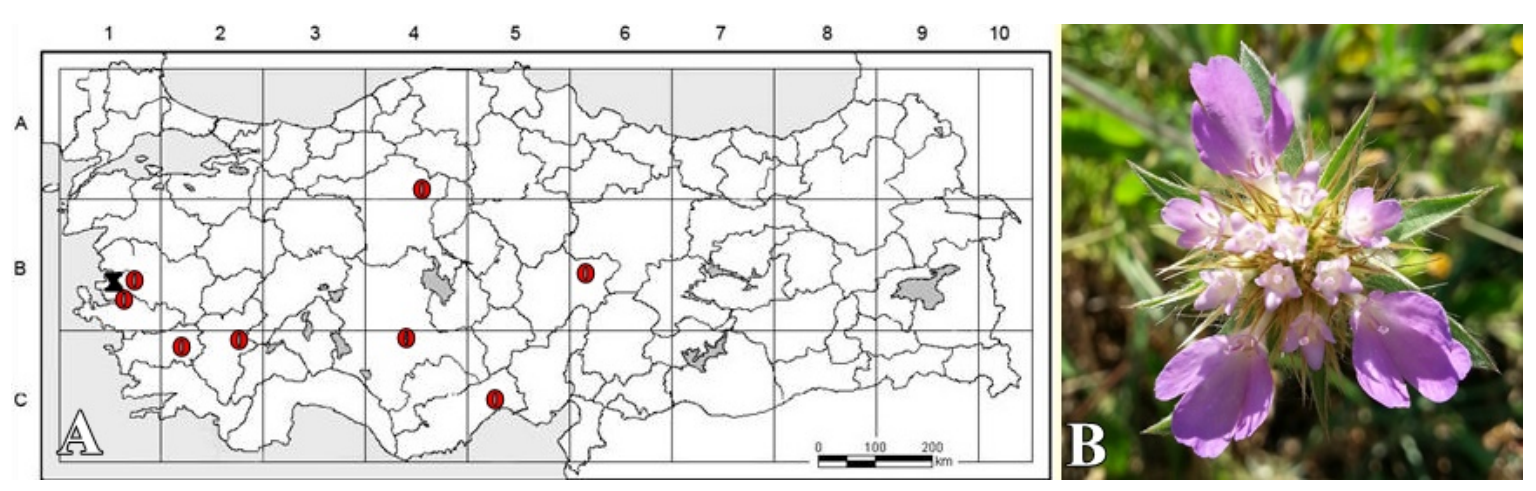

Şekil 1. S. hispidula'nın Türkiye'de dağılımı (o), çalışılan örneklerin toplandığı yer (x), B. Bitkinin çiçek durumu 


\section{Bulgular}

Kök: Kökten alınan enine kesitlerde, parçalanmış olan epidermis tabakası net olarak ayırt edilememektedir. Korteks tabakası, enleri boylarından belirgin bir şekilde büyük olan parankimatik hücrelerden oluşmuş durumdadır. Kesitte iletim dokusunu dıştan saran endodermis tabakası; boyları enlerinden büyük, 1-3 sıralı, düzenli ve sık dizilmiş olan hücrelerden oluşmaktadır. Kesitin merkezini ksilem elemanları doldurmuş durumdadır (Şekil 2, Tablo 1).

Gövde: Gövdeden alınan enine kesitlerde, en dışta çapları küçük ve tek sıralı hücrelerden oluşan epidermis tabakası bulunmaktadır. Bu tabakanın altında klorenkimatik yapıda olan hücrelerin varlığı belirgindir. Kesitte şekilleri çoğunlukla yuvarlağa yakın hücrelerden oluşmuş olan korteks parankiması, dar bir alanda sıkışmış durumdadır. Gövdede düzenli dizilim gösteren kolleteral iletim demetlerini parankimatik hücrelerden oluşan bir kın sarmaktadır. İletim demetlerinin aralarında sklerankimatik özellikte olan destek doku elemanlarının varlığg belirgindir. Kesitin merkezinde çapları büyük parankimatik hücrelerden oluşan öz bölgesi bulunmaktadır. Öz bölgesini oluşturan hücrelerin dışa doğru gidildikçe çeper kalınlaşması gösterdiği görülmüştür (Şekil 2, Tablo 1). Gövde kesitine genel olarak bakıldığında 1. ve 2. tip kapitat salgı tüyleri sıklıkla, 3. tip ve peltat salgı tüyleri ise az yoğunlukta gözlenmiştir. Bunun yanı sıra gövdede hidatot yapılarına da rastlanmıştır (Şekil 3).

Yaprak: Yapraktan alınan enine kesitlerde, yaprağın unifasiyal yapıda olduğu gözlenmiştir. Yaprağın her iki yüzeyinde de çoğunluğu 2. tip olan kapitat salgı tüyleri ve anizositik stoma tiplerine rastlanmıştır (Şekil 3). Mezofil tabakasında druz kristallerinin varlığı dikkat çekicidir. Mezofil tabakasında belirli aralıklarla sıralanan küçük çaplı iletim demetlerinin bazılarının etrafında, demet kını hücreleri bulunmaktadır (Şekil 2, Tablo 1).

Tablo 1. Scabiosa hispidula türünün anatomik ölçüm değerleri

\begin{tabular}{|c|c|c|c|c|c|c|c|c|c|c|c|c|}
\hline \multirow{3}{*}{$\begin{array}{l}\text { Kök } \\
\text { Korteks hücresi }\end{array}$} & \multicolumn{6}{|c|}{ En $(\mu \mathrm{m})$} & \multicolumn{6}{|c|}{ Boy $(\mu \mathrm{m})$} \\
\hline & \multicolumn{3}{|c|}{ Min.-Mak. } & \multicolumn{3}{|c|}{ Ort. \pm SS } & \multicolumn{3}{|c|}{ Min-Mak. } & \multicolumn{3}{|c|}{ Ort. \pm SS } \\
\hline & 61.65 & - & 97.68 & 78.26 & \pm & 09.28 & 14.45 & - & 34.10 & 24.50 & \pm & 04.81 \\
\hline Endodermis & 10.61 & - & 25.07 & 17.03 & \pm & 04.58 & 13.27 & - & 28.89 & 19.80 & \pm & 03.32 \\
\hline Floem & 09.73 & - & 26.25 & 21.33 & \pm & 04.75 & 06.78 & - & 12.97 & 09.67 & \pm & 01.81 \\
\hline Trake (Çap) & 17.40 & - & 53.98 & 39.19 & \pm & 11.76 & & & & & & \\
\hline \multicolumn{13}{|l|}{ Gövde } \\
\hline Epidermis hücresi & 07.05 & - & 17.94 & 12.38 & \pm & 02.60 & 06.17 & - & 12.94 & 09.54 & \pm & 02.36 \\
\hline Korteks hücresi & 08.23 & - & 25.58 & 14.28 & \pm & 04.41 & 07.05 & - & 22.05 & 13.22 & \pm & 05.18 \\
\hline Öz hücresi (Çap) & 12.64 & - & 48.52 & 28.25 & \pm & 10.66 & & & & & & \\
\hline Trake (Çap) & 05.58 & - & 13.52 & 10.34 & \pm & 02.21 & & & & & & \\
\hline \multicolumn{13}{|l|}{ Yaprak } \\
\hline Üst Kutikula & 03.24 & - & 07.08 & 04.52 & \pm & 01.32 & & & & & & \\
\hline Üst Epidermis & 22.41 & - & 39.52 & 30.67 & \pm & 05.18 & 16.51 & - & 33.92 & 26.02 & \pm & 04.80 \\
\hline Mezofil hücresi & 12.68 & - & 17.69 & 15.25 & \pm & 01.62 & 24.18 & - & 39.23 & 32.14 & \pm & 04.34 \\
\hline Trake (Çap) & 08.09 & - & 14.45 & 11.90 & \pm & 01.75 & & & & & & \\
\hline Alt Epidermis & 18.28 & - & 46.90 & 32.17 & \pm & 09.16 & 19.17 & - & 37.16 & 25.68 & \pm & 05.79 \\
\hline Alt Kutikula & 02.95 & - & 04.42 & 03.53 & \pm & & & & & & & \\
\hline
\end{tabular}




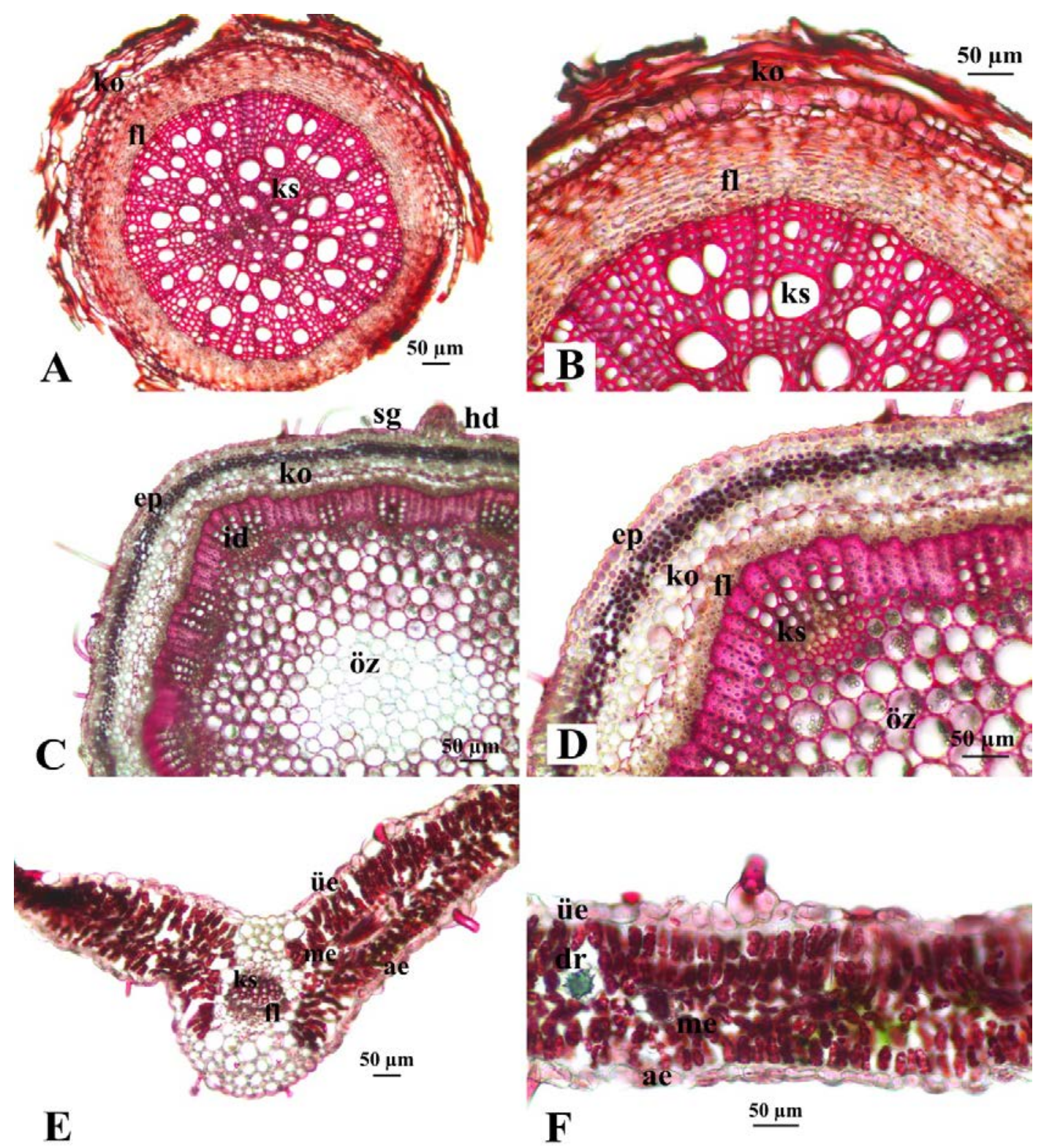

Şekil 2. S. hispidula türünün kök (A-B), gövde (C-D) ve yaprak (E-F) enine kesitleri (ölçek: $50 \mu \mathrm{m})$

ae: alt epidermis, ep: epidermis, fl: floem, id: iletim demeti, ko: korteks parankiması, ks: ksilem ku: kutikula, ku: kutikula, öz: öz bölgesi, pp: palizat parankiması, sg: salgı tüyü, sp: sünger parankiması, st: stoma üe: üst epidermis. 


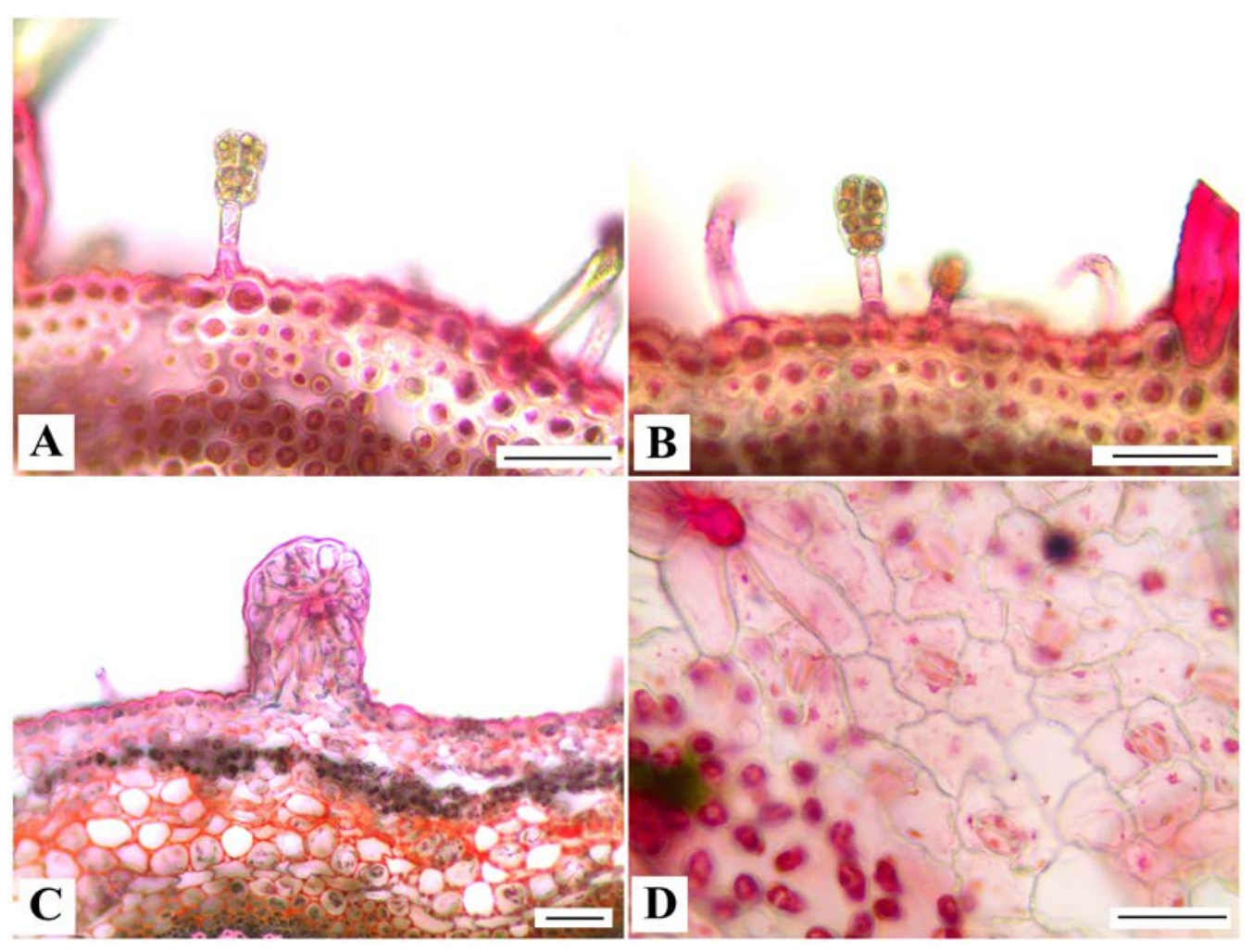

Şekil 3. S. hispidula türünün salgı tüyleri (A, B), hidatot (C) ve stoma (D) yapıları

\section{Tartıșma ve Sonuç}

Bu çalı̧̧mada Scabiosa hispidula türünün kök, gövde ve yaprak anatomileri incelenmiş ve sonuçlar familyaya ait diğer türlerle karşılaştırılmıştır.

S. hispidula türünün kök enine kesitinde 1-2 sıralı öz kolları görülmektedir. Caprifoliaceae familyasından Scabiosa rotata Bieb., türünde ve daha önceden Caprifoliaceae familyasında olan ancak, Adoxaceae E. Mey. familyasına dahil edilmiş olan Viburnum L. cinsinden Viburnum lantana L. ve V. orientale Pallas türlerinde de araştırmacılar tarafından 1-2 sıralı öz kolu gözlenmiştir [14, 15].

Gövde enine kesitinde salg1 tüyü ve hidatotlar dikkat çekicidir. Flora of Turkey'de $S$. hispidula'nın morfolojik deskripsiyonunda salgı tüylerinden hiç bahsedilmemiştir. Ayrıca S. rotata türünün sadece yaprak enine kesitlerinde az sayıda salgı tüylerine rastlanmış ve Dipsacoideae alt familyasında bu tip oluşumların nadiren bulunduğu belirtilmiştir. S.rotata'nın kök enine kesitlerinde, diğer türlerden farklı olarak druz kristallerine rastlandığ 1 belirtilmiştir. Türün yaprakta mezofilinde de druz kristallerinin bulunduğu ayrıca bu özeliğin alt familyanın diğer üyelerinde de bulunduğu belirtilmiştir [14]. Yapılan incelemeler sonucunda $S$. hispidula türünün yaprak mezofilinde druz kristallerine rastlanmış olmakla birlikte salgı tüyleri gövdede yoğun olmak üzere yaprakta da gözlenmiştir. Ayrıca S. rotata türünde olduğu gibi S. hispidula'nın yaprak enine kesitinde stoma komşu hücreleri üç tane anizositik stoma tipi gözlenmiştir. Viburnum cinsine ait bazı türlerde araştırıcılar tarafından mezofilde druz kristalleri gözlenmiş̧ir [15].

Daha önce Dipsacaceae familyasının bir üyesi olan Scabiosa cinsi moleküler çalışmalar sonucunda Caprifoliaceae familyasına dahil edilmişsir [16]. Scabiosa hispidula'nın anatomik yapısındaki salgı tüyleri ve druz kristalleri Caprifoliaceae familyasına ait türler için de karakteristik özelliklerdendir. Salgı tüylerinin Dipsacoideae alt familyasında nadiren bulunmasına karşın familyaya ait diğer türlerde 
bulunuyor olması ilginçtir. Bununla birlikte literatürde bu familyada hidatot gibi yapıların bulunduğuna dair veriler bulunmamaktadır.

\section{Kaynaklar}

[1] Verlaque R., "Etude Biosystematique et Phylogenetique des Dipsacaceae II. Caracteres Generaux des Dipsacaceae” Revista Citología Biologia Vegetation Botaniste, 8, 117-168, 1985

[2] Suyama C., Ueda K., “Taxonomic Revision of Scabiosa jezoensis (Dipsacaceae) in Japan” Kew Bulletin, 62, 95-105, 2007

[3] Göktürk S.R., “Caprifoliaceae.” Şu eserde: Güner, A., Aslan, S., Ekim, T., Vural, M., Babaç M.T. (edlr). Türkiye Bitkileri Listesi (Damarlı Bitkiler), Nezahat Gökyiğit Botanik Bahçesi ve Flora Araştırmaları Derneği Yayını, 313-324, İstanbul, 2012

[4] Verlaque R., "Etude biosystématique et phylogénétique des Dipsacaceae”. Ph.D. Thesis, Universitéde Provence, 406 p., Marseille, 1983

[5] Christopoulou C., Graikou K., Chinou I., "Chemosystematic Value of Chemical Constituents From Scabiosa hymettia (Dipsacaceae)”, Chemistry \& Biodiversity, 5, 318-323, 2008

[6] Metcalfe, C., R., Chalk, L.. “Anatomy of the Dicotyledons”. Oxford Vol.1, Oxford University Press, 810-816, 1950.

[7] Metcalfe, C., R., Chalk, L.. “Anatomy of The Dicotyledons”. Vol. II., London, 297p. 1983

[8] Perdetzoglou D.K., "Pharmacognostic, chemotaxonomic and morphological studies on the genus Scabiosa L. s. l. in Crete” University of Athens, Ph.D. Thesis, Greece, 1994

[9] Schulte-Scherlebeck H., "Kulturinformation zu Scabiosa caucasica” Zierpflanzenbau 11, 480, 1996.

[10] Romeijin G., Lammeren A.A.M., "Plant Regeneration Through Callus Initiation From Anthers and Ovules of Scabiosa columbaria” Plant Cell, Tissue and Organ Culture 56, 169-177, 1999

[11] Davis P.H., Chamberlain D.F., Phil D., Matthews A.V., "Flora of Turkey and the East Eagean Islands”, Vol. 4. Edinburgh Univ. Press, 144 p. 1972

[12] Algan, G., 1981. “Bitkisel Dokular İçin Mikroteknik”, Fırat Üniversitesi Fen-Edebiyat Fakültesi Yayınları, Bot. No:1, İstanbul.

[13] Bozdağ, B., Kocabaş, O., Akyol, Y., Özdemir, C. "Bitki Anatomisi Çalışmalarında El Kesitleri İçin Yeni Boyama Yöntemi” Marmara Pharmaceutical Botany, 20, 2, 184-190, 2016

[14] Panayır T., Baykal T. "Scabiosa rotata BIEB. (Dipsacaceae) Üzerinde Morfolojik ve Anatomik Araştırmalar”, Journal of Faculty of Pharmacy Ankara, 26 (1), 22-35, 1997

[15] Beyazoğlu O, Coşkunçelebi K., Odabaş H. “Anatomical Properties of wild Turkish Viburnum (Caprifoliaceae) Species”, Phytologia Balcanica 14 (1), 103 -110, 2008

[16] The Angiosperm Phylogeny Group, An update of the Angiosperm Phylogeny Group classification for the orders and families of flowering plants: APG II, Botanical Journal of the Linnean Society, 141, 399-436, 2003 